\title{
o-DGT Devices for the Determination of Emerging Contaminants in Aqueous Matrices
}

\author{
Tiago Wacheski, ${ }^{a}$ Emerson L. Y. Hara, ${ }^{a}$ Barbara G. S. Soares, ${ }^{a}$ Bruno J. G. da Silva, ${ }^{\circ a}$ \\ Gilberto Abate ${ }^{\circledR a}$ and Marco T. Grassi ${ }^{\circledR} * a$ \\ ${ }^{a}$ Departamento de Química, Universidade Federal do Paraná (UFPR), 81531-980 Curitiba-PR, Brazil
}

\begin{abstract}
Samplers based on the diffusive gradients in thin films for organics (o-DGT) were developed and applied in Brazilian aqueous matrices for the determination of four emerging contaminants (EC): 4-octylphenol, 4-nonylphenol, triclosan, and bisphenol A. The OASIS HLB resin used as the binding phase presented a high sorption capacity and the extraction associated with sonication, using a mixture of acetonitrile and methanol $\left(2: 1, \mathrm{v} \mathrm{v}^{-1}\right)$ as the solvent, provided a higher desorbed mass of the compounds. The diffusion coefficients determined experimentally were in the range of the values found in the literature and the $\mathrm{pH}$ and ionic strength influenced the sorption of some compounds by the binding phase. The substances were detected and quantified in tap and river water samples after 7 days of deployment using gas chromatography tandem mass spectrometry (GC-MS/MS). Finally, the results indicate deficiencies in the current wastewater, as well as water treatment systems, and could contribute in the future to the improvement of public policies on basic sanitation in Brazil.
\end{abstract}

Keywords: GC-MS/MS, passive samplers, OASIS HLB

\section{Introduction}

Emerging contaminants cover a wide spectrum of chemical substances, both synthetic and natural, whose concentration is not yet defined by environmental legislation in several countries, especially in Brazil. Contaminants include substances contained in pharmaceutical products, personal care, and hygiene products, pesticides, industrial and household products, surfactants, additives and solvents. ${ }^{1}$

The greatest concern with such contaminants is due to the fact that most of them are used and released continuously in the environment, mainly due to deficiencies in the sewer system. In the world ranking of basic sanitation, the coverage of this service in Brazil falls far short of European Union countries, is inferior to some countries in South America, and is similar to that of some places in North Africa. However, not so long ago, Brazil's economy was ranked among the ten largest in the world. Thus, the consumption patterns of a significant portion of the Brazilian population are similar to those of developed countries. $^{2-4}$

Even in ultra-trace concentrations, in the long run, emerging contaminants can cause endocrine disruption in

*e-mail: mtgrassi@quimica.ufpr.br humans and biota due to their toxicity. ${ }^{5,6}$ This can occur by direct ingestion or by biomagnification. In this way, the presence of emerging contaminants in the supply waters becomes an even greater challenge to be dealt with by society.

In this sense, determining the concentration of emerging contaminants and constant monitoring are prerequisites for understanding both the fate and the biogeochemical behavior of these compounds. Only in this way it is possible to assess the effects more effectively on ecosystems and human health. Even today, studies are conducted mainly through conventional sampling.

Although conventional sampling is the most commonly used strategy for monitoring organic contaminants in water, it generally needs samples which water volumes are greater than 1 L. Furthermore, there are several problems related to the samples transport, storage, treatment, and labor costs. ${ }^{7}$

Thus, an alternative in the determination of emerging contaminants is through passive sampling. More specifically with samplers based on the diffusive gradient in thin films, also called o-DGT. ${ }^{8}$ The passive sampler is approximately $4 \mathrm{~cm}$ in diameter. It is formed by a cap which window is $2.5 \mathrm{~cm}$ diameter by which the analytes diffuse from the sampled medium until they are sorbed in the binding layer and a base in the form of a piston (Figure 1). 


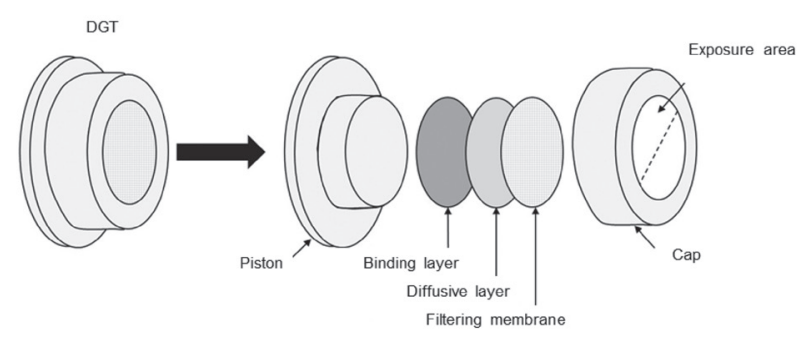

Figure 1. Schematic representation of an o-DGT device.

Between the cap and the piston, three membranes are added: a filtering membrane, which protects the other membranes of particles that may cause some damage to the diffusive layer, formed by a hydrogel (usually polyacrylamide or agarose) that is permeable and controls the diffusion of the species of interest, and the binding layer, composed by a material capable of sorbing the species of interest and which is immobilized on a hydrogel. ${ }^{9-11}$

Chen et al. ${ }^{8}$ was the first to propose the use of DGT samplers for the determination of organic contaminants, using in this case sulfamethoxazole as a model compound, and the XAD18 resin as a binding agent. After that, several papers describing the use of o-DGT were published, many of them prepared with HLB (hydrophilic-lipophilicbalanced) as the binding material, and used for the determination of pharmaceuticals and pesticides,${ }^{12}$ anionic pesticides, ${ }^{13}$ endocrine-disrupting chemicals (EDC),${ }^{14}$ nitro chlorobenzene chemicals, ${ }^{15}$ psychiatric pharmaceuticals, ${ }^{16}$ as well as target and suspect wastewater contaminants. ${ }^{17}$

All aforementioned studies were conducted in natural and wastewater samples with the detection being carried out using liquid chromatography coupled to different mass spectrometry detectors. Thus, this study aimed to determine the concentration of emerging contaminants in drinking and river waters. To the best of our knowledge, this is the first-time o-DGT samplers are used in tap water. Furthermore, what distinguishes this work from the others is the determination of the analytes which in this study was performed using a gas chromatography tandem mass spectrometry (GC-MS/ MS) system. This represented a greater challenge, due to the low volatility of the analytes they cannot be determined directly on the equipment. Then it was necessary to optimize a step of derivatization of the analytes in order to increase the sensitivity of the method.

\section{Experimental}

\section{Chemicals}

Four chemicals from different classes of emerging contaminants (EC) were selected for this study. Bisphenol A (BPA), bisphenol A- $d_{16}(\mathrm{BPA}-d)$, 4-octylphenol (OPN), and 4-nonylphenol (NPN) were purchased from Supelco (Cotia, Brazil) and triclosan (TCS) was obtained from SigmaAldrich which purity was $>99 \%$ (St. Louis, MO, USA). The derivative agent $\mathrm{N}, \mathrm{O}$-bis(trimethylsilyl)trifluoroacetamide (BSTFA) containing 1\% trimethylchlorosilane was also purchased from Sigma-Aldrich (St. Louis, MO, USA). Agarose was provided by Kasvi (Curitiba, Brazil) and OASIS HLB solid-phase extraction (SPE) cartridges (500 mg, $60 \mu \mathrm{m}$ particle size) were purchased from Waters (Milford, MA, USA). DGT polypropylene devices (piston and sleeve) were ordered from DGT Research Ltd. (Lancaster, England).

All solvents were high-performance liquid chromatography (HPLC) grade purchased from Merck (Darmstadt, Germany). Ultra-pure water used in the experiments was supplied by a Milli-Q purification system from Millipore (Billerica, MA, USA). Stock solutions of each chemical standard $\left(1000 \mathrm{mg} \mathrm{L}^{-1}\right)$ were prepared in methanol and stored in amber bottles at $-20{ }^{\circ} \mathrm{C}$ for later use.

\section{Diffusion and binding phase preparation}

Agarose gel was used as the diffusion gel in the o-DGT and its preparation followed the procedures previously described. ${ }^{8}$ A $1.5 \%\left(\mathrm{~m} \mathrm{v}^{-1}\right)$ agarose solution was prepared to dissolve the agarose powder in preheated ultrapure water and heated to $80{ }^{\circ} \mathrm{C}$ under constant stirring until the solution became transparent. Then, the solution was cast between two preheated glass plates separated by a $0.8 \mathrm{~mm}$ thickness spacer and left to cool down. After sectioning, the $2.5 \mathrm{~cm}$ diameter disks were stored in $0.05 \mathrm{~mol} \mathrm{~L}^{-1} \mathrm{NaNO}_{3}$ solution.

The binding phase was prepared through the immobilization of OASIS HLB reverse-phase polymer $\left(10 \%, \mathrm{~m} \mathrm{v}^{-1}\right)$ in agarose gel. The OASIS HLB was previously conditioned with methanol followed by ultrapure water and, then, removed from the cartridge. The OASIS HLB was added into agarose solution $\left(1.5 \%, \mathrm{~m} \mathrm{v}^{-1}\right)$, stirred, and pipetted into the pre-heated gel-casting containing $0.5 \mathrm{~mm}$ spacers. The binding phase was sectioned into $2.5 \mathrm{~cm}$ diameter disks and then stored in $0.05 \mathrm{~mol} \mathrm{~L}^{-1} \mathrm{NaNO}_{3}$ solution.

\section{Binding phase sorption capacity}

The OASIS HLB disks were exposed to aqueous solutions ( $\mathrm{pH} 5.8 \pm 0.1$ and $0.01 \mathrm{~mol} \mathrm{~L}^{-1} \mathrm{NaNO}_{3}$ ) with different concentrations of OPN, NPN, TCS, and BPA (100, 500,1000 and $2000 \mathrm{ng} \mathrm{mL}^{-1}$ ). The amber flasks containing the disks and the solution were left in an orbital shaker (Tecnal TE-420) for $17 \mathrm{~h}$ under stirring at $150 \mathrm{rpm}$ and controlled temperature $\left(25^{\circ} \mathrm{C}\right)$. 
Extraction of the compounds from the OASIS HLB disks was performed based on the methodology proposed by Chen et al. ${ }^{18}$ and consisted of transferring the OASIS HLB disks to $10 \mathrm{~mL}$ test tubes, followed by the addition of $5.00 \mathrm{~mL}$ of methanol and extraction for $20 \mathrm{~min}$ in the ultrasonic bath.

This step was repeated, and the two fractions of the solvent were combined and evaporated using a rotary vacuum concentrator (Christ, model RVC 2-18 CD plus). Finally, the substances were resuspended in $1.00 \mathrm{~mL}$ of methanol and filtered using a polytetrafluoroethylene (PTFE) syringe filter $(0.20 \mu \mathrm{m})$ for further derivatization and analysis by GC-MS/MS.

\section{Extraction evaluation}

OASIS HLB disks were kept immersed for $17 \mathrm{~h}$ in $5.0 \mathrm{~mL}$ of a $20 \mathrm{ng} \mathrm{mL}^{-1}$ mix aqueous solution of OPN, NPN, TCS, and BPA (0.01 mol L-1 $\mathrm{NaNO}_{3}$ and pH 6.0) at $150 \mathrm{rpm}$ and $25^{\circ} \mathrm{C}$. After this time, the disks were transferred to $10 \mathrm{~mL}$ test tubes and extraction was performed as described in the previous section, however, using different solvents, such as methanol, acetonitrile $(\mathrm{ACN})$, acetonitrile:methanol $\left(2: 1, \mathrm{v} \mathrm{v}^{-1}\right)$, methanol: toluene:dichloromethane $\left(1: 1: 8, \mathrm{v} \mathrm{v}^{-1}\right)$ and acetonitrile:ethyl acetate $\left(1: 1, \mathrm{v} \mathrm{v}^{-1}\right)$.

After choosing the solvent, tests were carried out involving the number of extractions that consisted of using one to three extractions with $3.00 \mathrm{~mL}$ of solvent and employing $20 \mathrm{~min}$ of sonication at each extraction. Finally, choosing the number of extractions, the extraction time was evaluated using the ultrasonic bath for $2,5,10$, and $20 \mathrm{~min}$. For both tests, the sorption step of the substances by the OASIS HLB disks was performed under the same conditions used in the solvent evaluation.

\section{Elution factor $\left(\mathrm{f}_{\mathrm{e}}\right)$}

Four milliliters of a $100 \mathrm{ng} \mathrm{mL}^{-1}$ mix aqueous solution of OPN, NPN, TCS, and BPA $\left(0.01 \mathrm{~mol} \mathrm{~L}^{-1} \mathrm{NaNO}_{3}\right.$ and pH $5.8 \pm 1$ ) were added in $20 \mathrm{~mL}$ amber flasks containing the OASIS HLB disks. The flasks were left on an orbital shaker (Tecnal TE-420) for $18 \mathrm{~h}$ under stirring at $150 \mathrm{rpm}$ and temperature of $25^{\circ} \mathrm{C}$. The extraction was carried out using the condition optimized and the substances were determined by gas chromatography.

\section{Diffusion coefficient measurements}

DGT devices assembled with OASIS HLB disks and agarose gel were kept into a $10 \mathrm{ng} \mathrm{mL}^{-1}$ aqueous solution containing the four mixed analytes $\left(\mathrm{pH} 6.0\right.$ and $0.01 \mathrm{~mol} \mathrm{~L}^{-1}$ $\mathrm{NaNO}_{3}$ ) under stirring at $750 \mathrm{rpm}$ and constant temperature at $25{ }^{\circ} \mathrm{C}$. Devices were removed from the solution at different time intervals (up to $64 \mathrm{~h}$ ) for further extraction of the retained substances in the binding phase. The mass (M) of each substance diffused by the agarose gel was calculated using equation 1 , where $C_{e}$ represents the concentration of the substance extracted from the OASIS HLB disk, $\mathrm{V}_{\mathrm{e}}$ is the final volume of the solvent in the vial and $f_{e}$ the elution factor of each substance obtained after the extraction evaluation.

$\mathrm{M}=\frac{\mathrm{C}_{\mathrm{e}} \mathrm{V}_{\mathrm{e}}}{\mathrm{f}_{\mathrm{e}}}$

After obtaining the slope of the linear plot (k) between the diffused mass of the compound and time of the measurement, the diffusion coefficient $\left(\mathrm{D}, \mathrm{cm}^{2} \mathrm{~s}^{-1}\right)$ was calculated using the equation 2 :

$\mathrm{D}=\frac{\mathrm{k} \Delta \mathrm{g}}{\mathrm{CA}}$

where $\Delta \mathrm{g}$ is the diffusive gel thickness, $\mathrm{C}$ is the initial compound concentration in the solution, and $\mathrm{A}$ is the area of the window in the device cap.

\section{Effect of $\mathrm{pH}$ and ionic strength on the uptake of EC}

The o-DGT devices were kept in solutions containing the substances $\left(20 \mathrm{ng} \mathrm{mL}^{-1}\right)$ using different $\mathrm{pH}$ values $(5$, 6,7 , and 8) and the salt concentration (0.001, 0.01, 0.1, and $0.3 \mathrm{~mol} \mathrm{~L}^{-1}$ of $\mathrm{NaNO}_{3}$ ). For $\mathrm{pH}$ tests, the ionic strength was kept constant $\left(0.01 \mathrm{~mol} \mathrm{~L}^{-1}\right)$ and the adjustment was performed using dilute solutions of $\mathrm{HCl}$ and $\mathrm{NaOH}$. To investigate the effect of ionic strength on o-DGT performance, $\mathrm{pH}$ was adjusted to 6.0 and different masses of $\mathrm{NaNO}_{3}$ were used to obtain the desired ionic strength. For both experiments, the exposure time was $15 \mathrm{~h}$ at $25{ }^{\circ} \mathrm{C}$.

\section{Application of o-DGT in aqueous matrices}

The application of o-DGT was performed in the laboratory using samples of tap water and surface water collected from the Iraí River ( $25^{\circ} 26^{\prime} 40.6^{\prime \prime}$; $49^{\circ} 08^{\prime} 33.9^{\prime \prime} \mathrm{W}$ ). The tap water was sampled at our research laboratory. The tap was left open for a few minutes before transferring the water to the recipient where devices were deployed in about $115 \mathrm{~L}$ of the sample under stirring using an aquarium pump. The sampling time was 7 days with 
temperature during the development of the experiment of $21 \pm 2{ }^{\circ} \mathrm{C}$ and $\mathrm{pH} 6.8$.

About $60 \mathrm{~L}$ of Iraí River water was collected in July 2017 from a point located in the city of Piraquara, the metropolitan area of Curitiba. The sampling was performed in order to preserve the integrity of the water sample until the arrival at the laboratory. Once at the laboratory, the sample was filtered using a metal sieve and transferred to a $100 \mathrm{~L}$ aquarium. The sample was stirred using the aquarium pump, the $\mathrm{pH}$ measured was 7.4 and the mean temperature during the 7 days of sampling was $17.3 \pm 0.9{ }^{\circ} \mathrm{C}$.

\section{Derivatization and GC-MS/MS analysis}

Substances have undergone a derivatization reaction before being analyzed by GC-MS/MS. The solvent containing the EC was evaporated in a rotary vacuum concentrator (Christ, model RVC 2-18 CDplus) and then $20 \mu \mathrm{L}$ of BSTFA were added. The reaction was performed in a domestic microwave under $840 \mathrm{~W}$ for $5 \mathrm{~min}$. Finally, the derivatizing agent was evaporated and the substances were resuspended in hexane. Quantification of EC was performed using a Shimadzu 2010-Plus gas chromatograph coupled to a triple quadrupole mass detector TQ-8040 (Kyoto, Japan).

The compounds were injected by a Shimadzu automatic sampler (AOC-5000) and separation was carried out on an Rtx-5MS capillary column $(30 \mathrm{~m} \times 0.25 \mathrm{~mm}$ i.d., $0.25 \mu \mathrm{m}$ film thickness), also from Shimadzu. Helium (purity 99.999\%) was employed as carrier gas at a constant column flow of $1.0 \mathrm{~mL} \mathrm{~min}^{-1}$.

The initial GC oven temperature was $80^{\circ} \mathrm{C}$, which was maintained for $1 \mathrm{~min}$, followed by heating to $300^{\circ} \mathrm{C}$ at a rate of $10^{\circ} \mathrm{C} \mathrm{min}^{-1}$ and then kept on this temperature for $10 \mathrm{~min}$. The total analysis time was $33 \mathrm{~min}$. Injections $(1 \mu \mathrm{L})$ were done in the splitless mode, using an injector temperature of $250{ }^{\circ} \mathrm{C}$. The transfer line and ion source were kept at 300 and $250{ }^{\circ} \mathrm{C}$, respectively. The triple quadrupole mass spectrometer was operated in the electron ionization mode (EI, $70 \mathrm{eV}$ ) and the mass spectrometer acquisition mode was set to multiple reaction monitoring (MRM) employing the parameters shown in Table 1.

The analytical curves were plotted in triplicate: 5,10 , $25,50,100,250$, and $500 \mu \mathrm{g} \mathrm{L} \mathrm{L}^{-1}$ bisphenol A- $d_{16}$ was used as the internal standard. Limits of detection (LOD) and quantification (LOQ) (equations 3 and 4) were calculated considering the relative standard deviation (RSD) of the linear coefficient of the curves (s) and the angular coefficient of the curves $(\mathrm{S})$.

$\mathrm{LOD}=3 \frac{\mathrm{s}}{\mathrm{S}}$

$$
\mathrm{LOQ}=10 \frac{\mathrm{s}}{\mathrm{S}}
$$

\section{Results and Discussion}

\section{Binding phase sorption capacity}

The uptake of the four compounds increased with its concentration in solution up to the highest concentration tested, as seen in Figure 2, which indicates there was no saturation on OASIS HLB disks.

As TCS presents a water solubility of $2.0 \mathrm{mg} \mathrm{L}^{-1}$ at $30^{\circ} \mathrm{C}$, the lowest solubility among the substances, this value was the maximum concentration of the mixed solution on this test. The water solubility of OPN and NPN at $20.5^{\circ} \mathrm{C}$ is 12.6 and $5.4 \mathrm{mg} \mathrm{L}^{-1}$, respectively. Finally, at $25^{\circ} \mathrm{C}$ BPA has a water solubility of approximately $200 \mathrm{mg} \mathrm{L}^{-1} .19,20$ The ECs are found in much lower concentrations in aquatic environments than those used in this experiment, so it is reasonable to consider that the use of the OASIS HLB disk as the binding phase in the o-DGT sampler would be effective, not presenting the risk of saturation of this phase even after long periods of sampling. Also, taking into account the mass of OASIS HLB per disk, about $25 \mathrm{mg}$, it was possible to prove the high sorption capacity of this binding phase at the $\mathrm{pH}$ and ionic strength conditions employed.

Table 1. MRM transitions

\begin{tabular}{|c|c|c|c|c|c|c|c|}
\hline \multirow{2}{*}{ Compound } & \multirow{2}{*}{$\begin{array}{l}\text { Precursor ion } \\
\qquad(\mathrm{m} / \mathrm{z})\end{array}$} & \multicolumn{2}{|c|}{ Quantification } & \multicolumn{2}{|c|}{ Confirmation (1) } & \multicolumn{2}{|c|}{ Confirmation (2) } \\
\hline & & MRM transition & $\mathrm{CE} / \mathrm{V}$ & MRM transition & $\mathrm{CE} / \mathrm{V}$ & MRM transition & $\mathrm{CE} / \mathrm{V}$ \\
\hline $\mathrm{BPA}$ & 357 & $357.00>73.10$ & 27 & $357.00>191.10$ & 21 & $357.00>207.10$ & 12 \\
\hline BPA- $d$ & 368 & $368.00>73.10$ & 24 & $368.00>197.10$ & 24 & $368.00>296.10$ & 27 \\
\hline OPN & 179 & $179.00>73.10$ & 18 & $179.00>58.00$ & 42 & $179.00>105.10$ & 12 \\
\hline NPN & 179 & $179.00>73.10$ & 21 & $179.00>58.00$ & 42 & $179.00>105.10$ & 12 \\
\hline TCS & 200 & $200.00>185.00$ & 18 & $200.00>170.00$ & 30 & $200.00>134.90$ & 48 \\
\hline
\end{tabular}

MRM: multiple reaction monitoring; CE: collision energy; BPA: bisphenol A; BPA- $d$ : bisphenol A- $d_{16}$; OPN: 4-octylphenol; NPN: 4-nonylphenol; TCS: triclosan. 

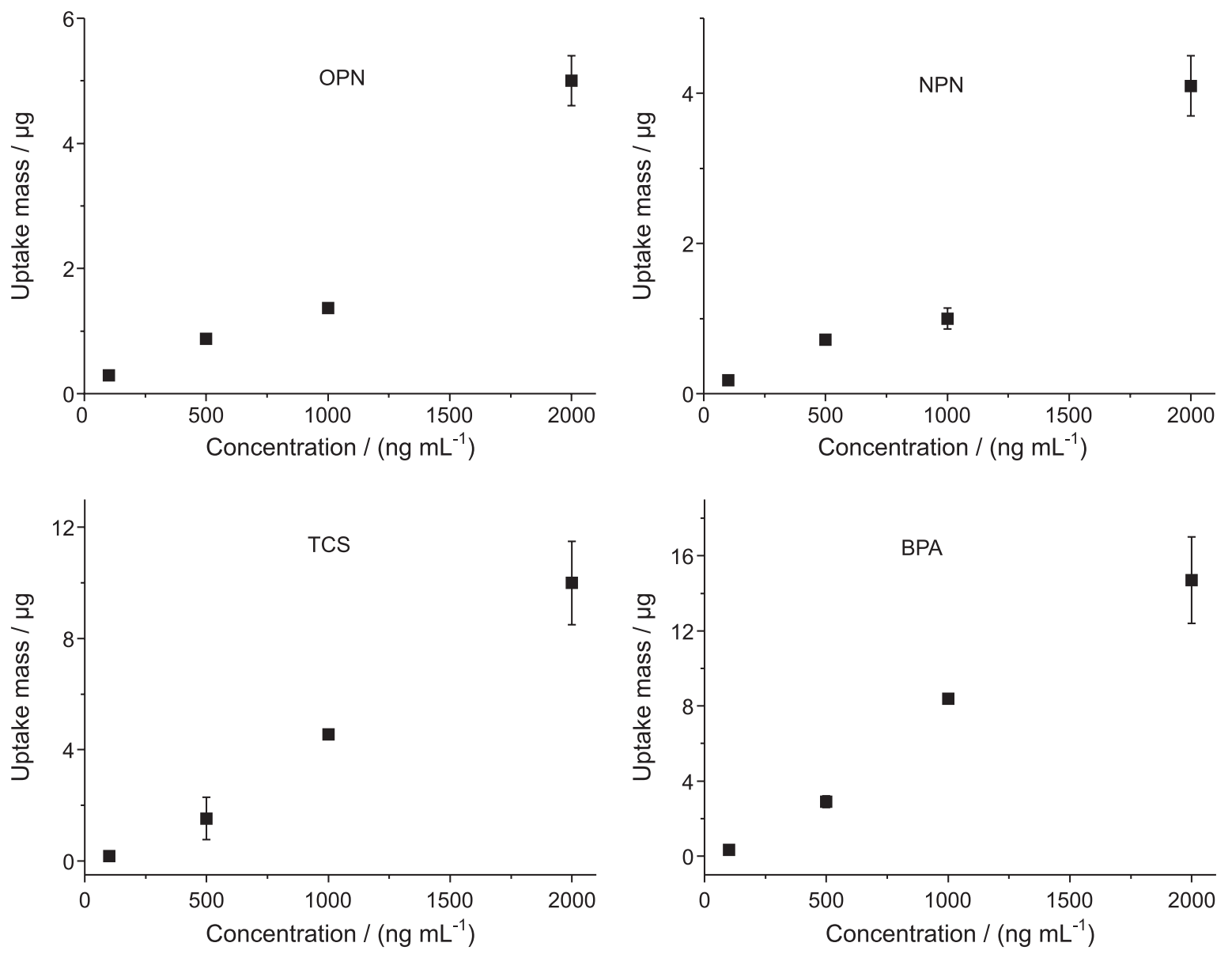

Figure 2. Mass extracted from OASIS HLB disks that were exposed to different concentrations of the substances at pH $5.8 \pm 0.1$ and salt concentration of $0.01 \mathrm{~mol} \mathrm{~L}^{-1}$. Error bars: standard deviation of four replicates.

\section{Extraction evaluation}

Figure 3 shows the average peak area values for each substance extracted from the OASIS HLB disk employing different solvents.

It is important a binding phase that shows a high sorption capacity and also provides a subsequent recovery of the substances. As the substances retained on the OASIS HLB disks belong to different classes of $\mathrm{EC}$ and thus have different physicochemical properties, it would be interesting to find the solvent that has a good interaction with the compounds in order to improve the extraction. Therefore, solvents and solvent mixtures that have been used in the extraction of EC and reported in the literature ${ }^{21}$ were tested.

The mixture $\mathrm{ACN} / \mathrm{MeOH}$ provided a higher average peak area for the compounds and lower estimates of standard deviation. The use of the ACN resulted in the highest peak area average for OPN, but it also presented the highest standard deviation that indicates a lower precision between the values of the triplicates. Further, ACN has a higher boiling point than $\mathrm{MeOH}$ (81.65 and $64.6^{\circ} \mathrm{C}$, respectively), and therefore it needs a longer time

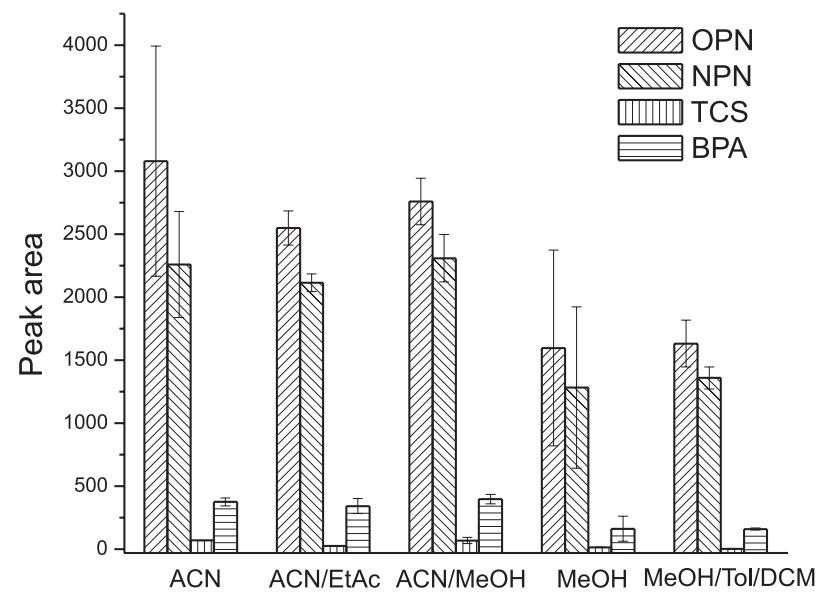

Figure 3. Average peak area values of each substance extracted from the OASIS HLB disk employing different solvents. ACN: acetonitrile; ACN/EtAc: acetonitrile:ethyl acetate $\left(1: 1, \mathrm{v} \mathrm{v}^{-1}\right)$; ACN/MeOH: acetonitrile:methanol $\left(2: 1, \mathrm{v} \mathrm{v}^{-1}\right)$; $\mathrm{MeOH}$ : methanol; $\mathrm{MeOH} / \mathrm{Tol} / \mathrm{DCM}$ : methanol:toluene:dichloromethane $\left(1: 1: 8, \mathrm{v} \mathrm{v}^{-1}\right)$; error bars: standard deviation of three replicates.

to volatilize before carrying out the derivatization reaction. For these reasons, the mixture $\mathrm{ACN} / \mathrm{MeOH}$ was chosen as the extractor solvent. 
The average peak area increased significantly with the number of extractions, as shown in Figure 4, indicating an efficient extraction of the substances. However, several extractions would result in a larger solvent volume, and, consequently, it would require more time in the evaporation step. Also, the maximum volume of the tubes from the vacuum concentrator used is $10 \mathrm{~mL}$, which makes it impossible to evaporate larger volumes.

As displayed in Figure 5, two minutes of sonication on OASIS HLB disks provided a higher average mass extracted for most substances. From the time of ten minutes, the disintegration of some disks was observed, which caused the release of OASIS HLB in the tube containing the solvent after extraction.

Thus, until the sample is filtered, the substances may have been retained again by OASIS HLB resulting in smaller amounts of extracted mass, and it also may have influenced the significant values of standard deviations. For these reasons and for allowing a significant decrease in extraction time when comparing to previous studies, ${ }^{22}$ two minutes of sonication was chosen as the standard time in the extraction step.

Finally, the elution factor $\left(f_{e}\right)$ of the substances in the
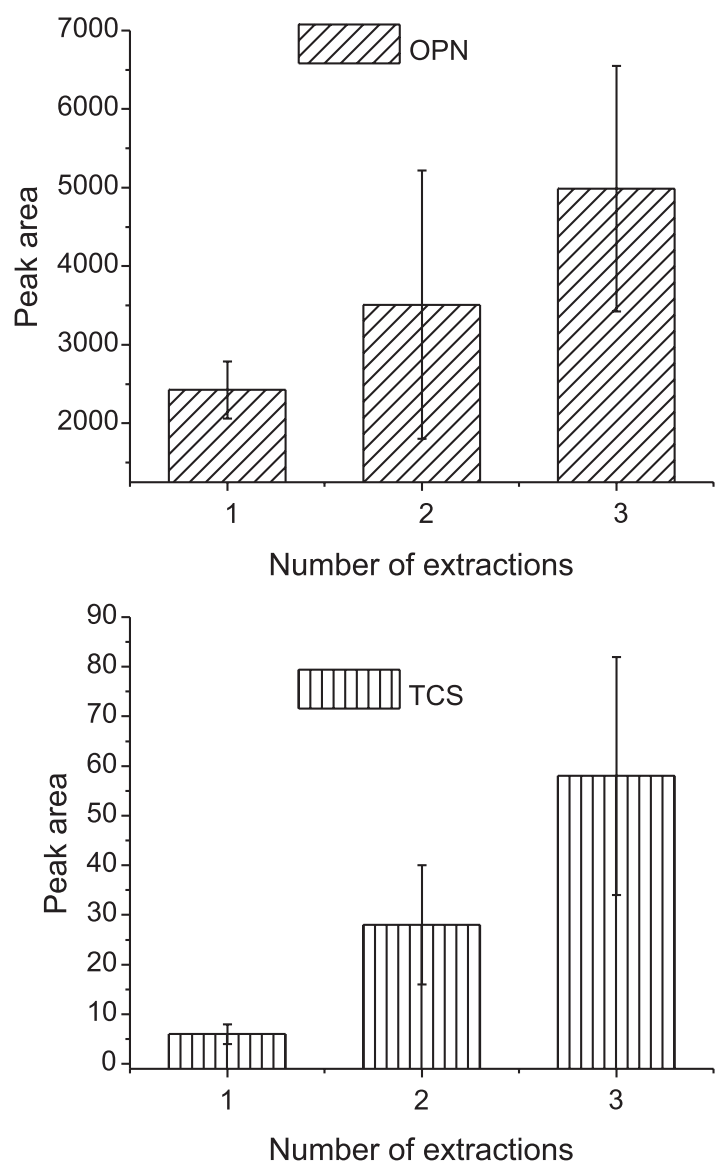

OASIS HLB disk was estimated. This factor is related to the recovery of the retained compounds, and it is important in order to avoid an underestimation or overestimation of the concentration after the sampling using o-DGT. Three extractions with $\mathrm{ACN} / \mathrm{MeOH}$ employing two minutes of sonication between each extraction provided an $\mathrm{f}_{\mathrm{e}}$ of 0.66 ; $0.44 ; 0.47$ and 0.70 for OPN, NPN, TCS, and BPA, respectively.

\section{Diffusion coefficient measurement}

Challis et al. ${ }^{23}$ proposed a configuration of o-DGT samplers consisting only of the binding phase (OASIS HLB immobilized on the agarose gel) and the diffusion gel (agarose gel), without the polyethersulfone (PES) membrane as presented on the first study, after tests proved the membrane was able to retain significantly some pharmaceuticals and pesticides. Compounds having a moderate or low polar character tend to be retained in the PES membrane, which is the case of the compounds in this present study.

Therefore, it was decided to adopt this configuration to determine the apparent diffusion coefficient (D') of EC on
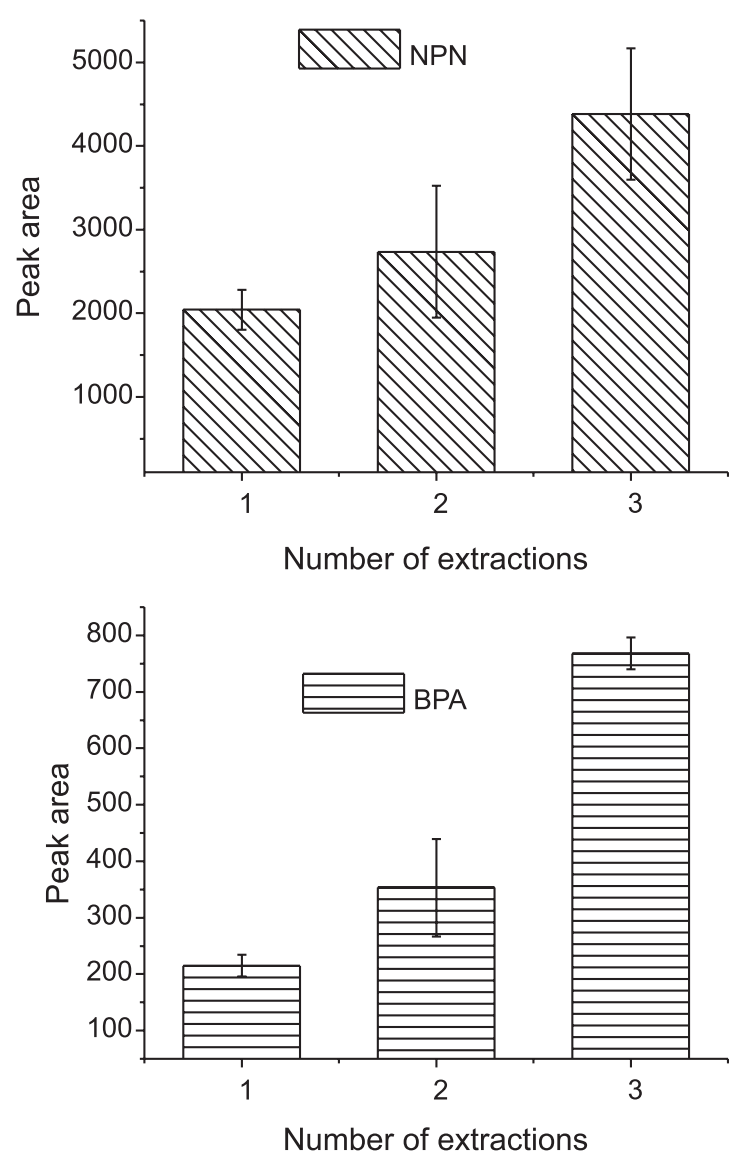

Figure 4. Average values of the peak areas of each substance extracted from OASIS HLB disks employing a different number of extractions with $3.0 \mathrm{~mL}$ of ACN/MeOH $\left(2: 1, \mathrm{v} \mathrm{v}^{-1}\right)$. Error bars: standard deviation of three replicates. 

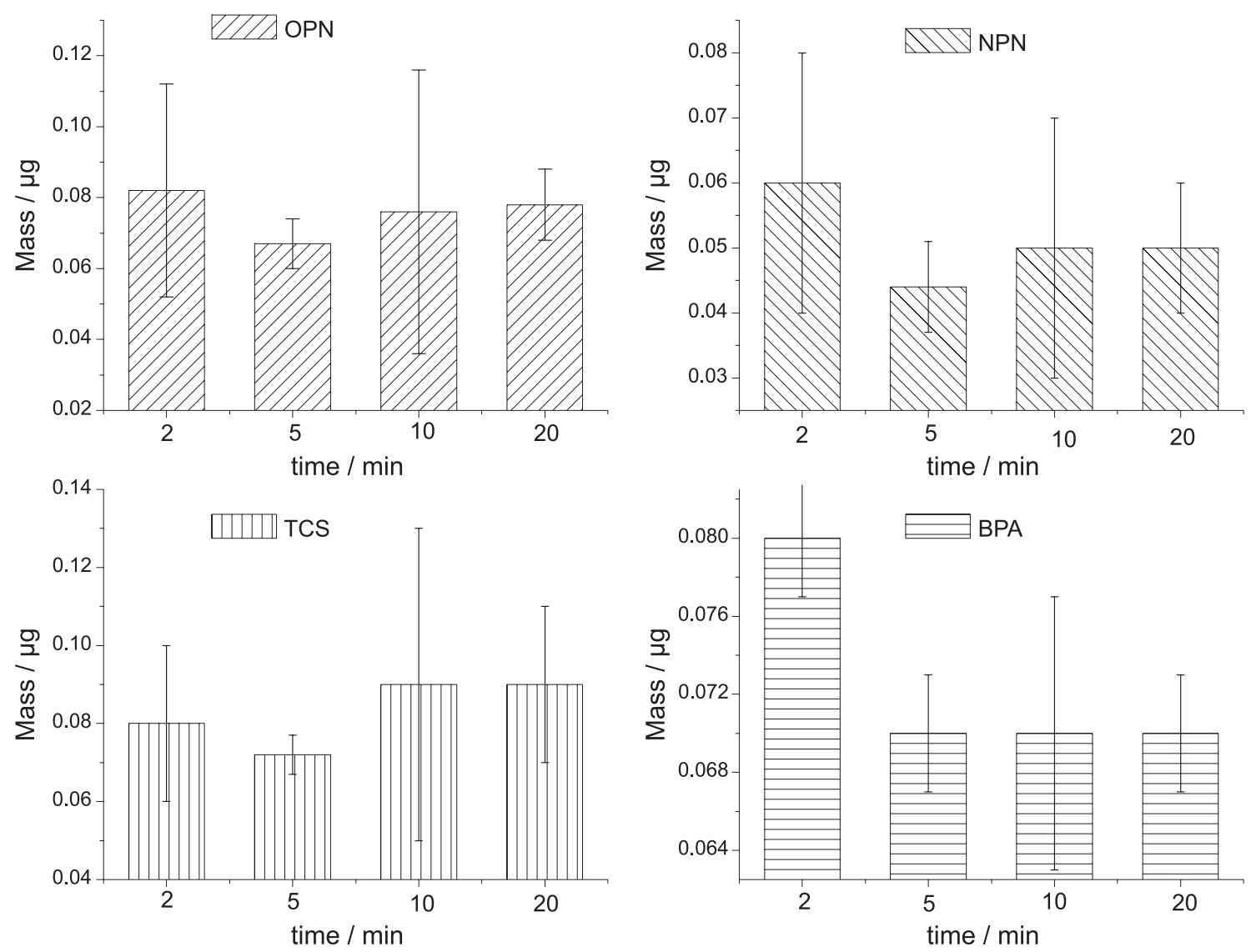

Figure 5. Average masses of substances extracted using different sonication times. Error bars: standard deviation of three replicates.

the agarose gel. The term "apparent" is used to indicate the diffusion coefficient was not determined by using a diffusion cell, but performed indirectly, i.e., applying the o-DGT samplers at different exposure times and subsequently determining the mass of the substances diffused by the agarose gel. From the angular coefficient obtained by the correlation between the mass and time of the measurement (Figure 6), the D' was calculated using equation 2.

The coefficient of determination for all substances was greater than 0.98 and values of D' for OPN, NPN, TCS and BPA were $2.95 \times 10^{-6}, 0.750 \times 10^{-6}, 3.37 \times 10^{-6}$, and $4.69 \times 10^{-6} \mathrm{~cm}^{2} \mathrm{~s}^{-1}$, respectively. Here it is important to contrast the indirect method adopted to determine D' in this work allows only an estimation of this parameter. In the literature ${ }^{24}$ it is possible to find D for some classes of organic substances in the agarose gel, however, they were determined using a diffusion cell. Chen et al. ${ }^{24}$ determined the $\mathrm{D}$ for several antibiotics, with values varying from $0.58 \times 10^{-6}$ to $6.24 \times 10^{-6} \mathrm{~cm}^{2} \mathrm{~s}^{-1}$ at $25^{\circ} \mathrm{C}$. For some drugs and pesticides, values of 1.02 to $4.74 \times 10^{-6} \mathrm{~cm}^{2} \mathrm{~s}^{-1}$ at 5 , 13 , and $23{ }^{\circ} \mathrm{C}$ were found.

By using the diffusion cell, Chen et al..$^{24}$ reported a D at $25{ }^{\circ} \mathrm{C}$ for 4-tert-octylphenol $\left(4.34 \times 10^{-6} \mathrm{~cm}^{2} \mathrm{~s}^{-1}\right)$ and nonylphenol $\left(4.13 \times 10^{-6} \mathrm{~cm}^{2} \mathrm{~s}^{-1}\right)$. These values differ from the values found in this study and it may be caused by the differences in the measuring method. So far, there is no D for TCS used on the DGT technique in literature for comparison.

Zheng and co-workers ${ }^{25}$ reported an average value of $4.78 \times 10^{-6} \mathrm{~cm}^{2} \mathrm{~s}^{-1}$ for the apparent diffusion coefficient for BPA, and more recently, Chen et al. ${ }^{26}$ found a value of $4.80 \times 10^{-6} \mathrm{~cm}^{2} \mathrm{~s}^{-1}$. These values are consistent with the D' found in this study, within $3 \%$ of the values presented in the literature. The diffusion coefficients for some organic substances are slightly smaller in comparison to the coefficients of metallic species. According to Chen et al. ${ }^{26}$ this lower value may be due to the larger size of the organic molecules.

The agarose gel used in the diffusion coefficient measurement underwent the extraction step in order to evaluate its sorption capacity. No increase in sorption of the substances was observed in the time interval studied (up to $60 \mathrm{~h}$ ), and the mean value of the extracted mass for all the substances was less than $1 \%$ of the total mass available in the solution in which they were exposed. Therefore, the agarose gel could be used as a diffusive gel in o-DGT for the determination of OPN, NPN, TCS, and BPA without interfering in the sorption by the OASIS HLB disk. 

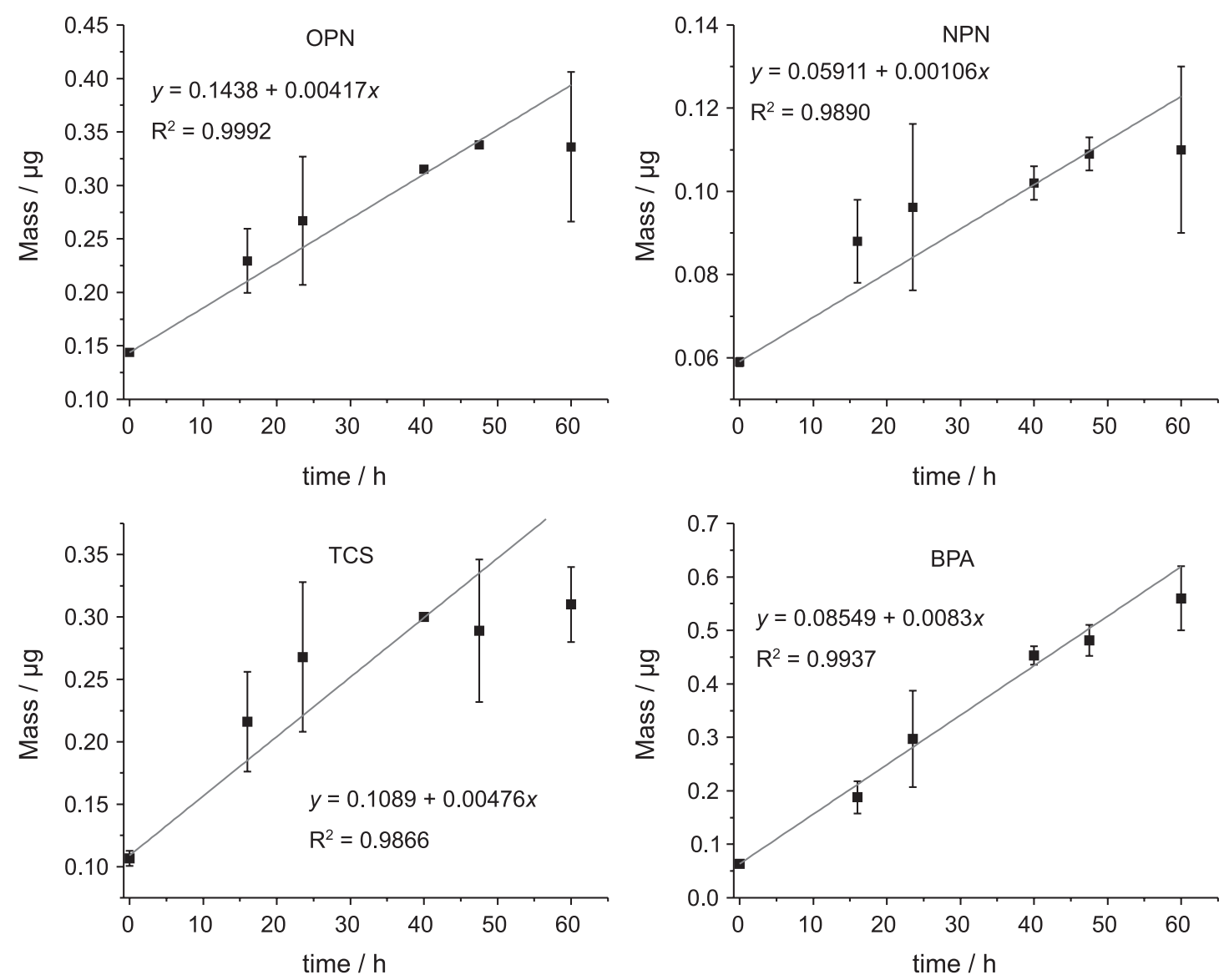

Figure 6. Linear correlation between mass diffused through the gel and the exposure time at $25^{\circ} \mathrm{C}, 0.01 \mathrm{~mol} \mathrm{~L}^{-1} \mathrm{NaNO}_{3}$, and $\mathrm{pH}$ 6.0. Error bars: standard deviation of three replicates.

Effect of $\mathrm{pH}$ and ionic strength on the uptake of EC

Generally, the $\mathrm{pH}$ found in natural waters is in the range of 5 to 9 , and the ionic strength can vary from 0.01 (surface waters) to $0.5 \mathrm{~mol} \mathrm{~L}^{-1}$ (seawater). ${ }^{27}$ Thus, the applicability of o-DGT in aqueous matrices was studied by employing it in different $\mathrm{pH}$ and ionic strength. The performance of o-DGT by varying the $\mathrm{pH}$ can be observed in Figure 7.

A one-way analysis of variance (ANOVA) showed a significant difference in sorption as a function of $\mathrm{pH}$ for NPN and BPA at $95 \%$ confidence $(\alpha=0.05)$. Chen et al. ${ }^{24}$ observed a higher sulfamethoxazole concentration at $\mathrm{pH} 5$, using the XAD18 resin immobilized on agarose as binding phase, and this $\mathrm{pH}$ could have caused a change in the speciation of the antibiotic and affected the interaction with the XAD18 resin. The main sorption mechanism is related to the hydrophobic interactions and, thus, neutral molecules are preferentially more retained by the resin, while sulfamethoxazole molecules with negative charges at higher $\mathrm{pH}$ would suffer electrostatic repulsion. According to the $\mathrm{p} K_{\mathrm{a}}$ of the analytes and the $\mathrm{pH}$ range evaluated, no structural change was expected, and thus there should be no effect on the sorption. However, OPN and NPN presented

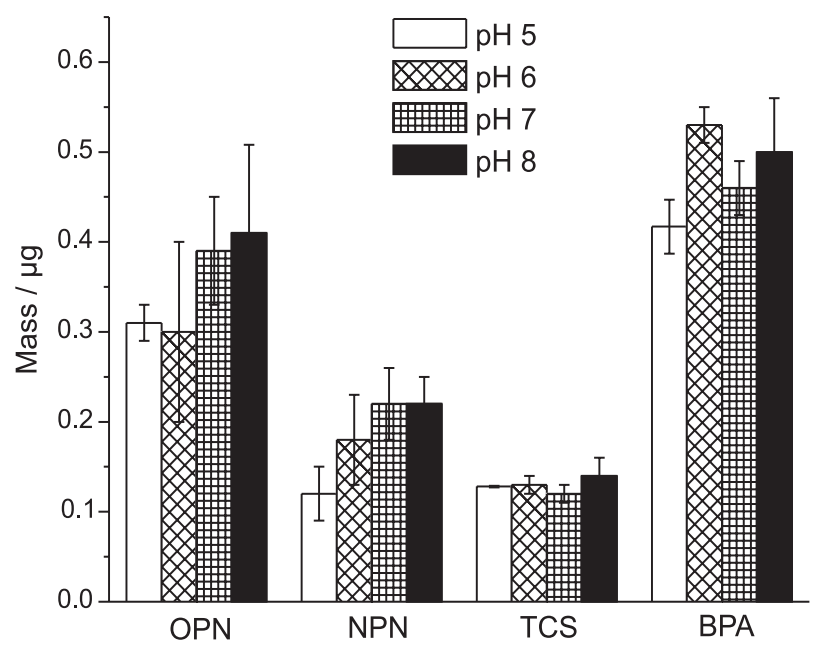

Figure 7. Mass of each compound taken up by the OASIS HLB disk in different $\mathrm{pH}$ values. Error bars: standard deviation of three replicates.

higher sorption when the $\mathrm{pH}$ increased.

There was a significant difference in sorption (ANOVA, $\alpha=0.05$ ) when the ionic strength was increased. Most of the substances were less retained by OASIS HLB in higher ionic strength, unlike the BPA that presented a lower average mass at lower ionic strength (Figure 8). 


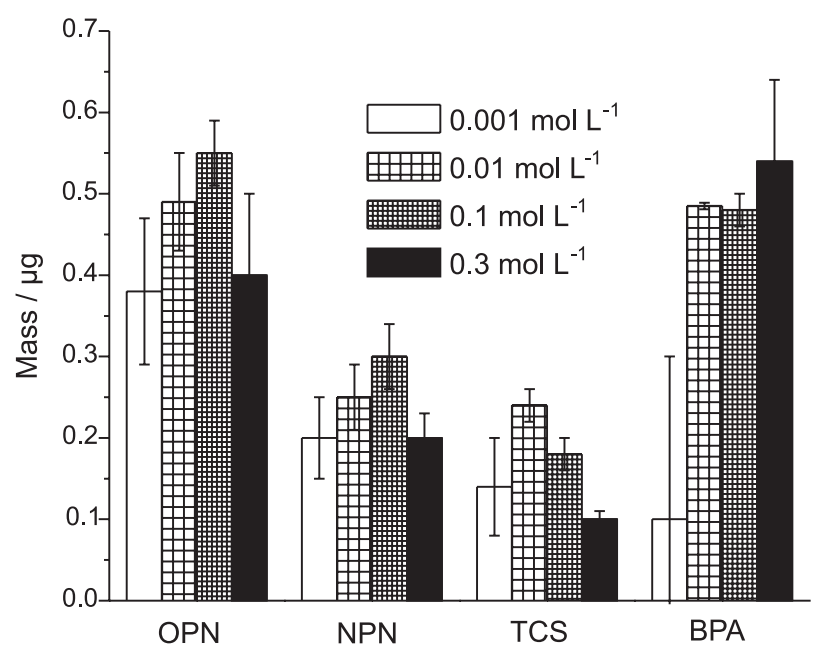

Figure 8. Ionic strength effect on the uptake of the substances by the OASIS HLB disk. Error bars: standard deviation of three replicates.

OASIS HLB is composed of a combined lipophilic (divinylbenzene) polymer with a hydrophilic polymer ( $n$-vinyl pyrrolidine), and it has been widely used in SPE and passive sampling. However, there is little information on the partitioning behavior of different organic substances in OASIS HLB in aquatic systems. ${ }^{15}$ The influence of factors, such as temperature, $\mathrm{pH}$, and ionic strength, on the sorption equilibrium of compounds in OASIS HLB, has been investigated. Experiments indicated the sorption of pharmaceuticals and biocides by OASIS HLB is dependent on the $\mathrm{pH}$ and it is attributed to the increase of the negative potential in the resin at higher $\mathrm{pH}$ values that could lead to electrostatic interactions. A decrease in the sorption of substances was observed with the increase of the ionic strength, and it may be caused by the competition between the ions from the added salt and the compounds for the sorption sites in the OASIS HLB..$^{12}$ Therefore, the difference in sorption found in this study may be due to the partitioning effects on OASIS HLB under different aqueous matrices conditions.

Recovery tests and application of o-DGT in aqueous matrices

To ensure the quality assurance and quality control (QA/QC) of the method recovery tests were performed at three levels of concentration $(n=3)$. The concentrations studied were $0.4,1.0$, and $4.0 \mu \mathrm{g} \mathrm{L}^{-1}$ of BPA, OPN, NPN, and TCS. For this, the o-DGT devices were assembled with the diffusive and binding phases and applied separately in solutions containing the analytes for 7 days. Subsequently, the devices were disassembled, and the binding phases were subjected to the extraction procedure with solvent. The solvent was evaporated, the analytes were submitted to derivatization, and the extract was injected into the GC-MS/MS. The recovery values ranged from 70 to $120 \%$ with RSD of up to $20 \%$ for all the analytes, indicating a satisfactory extraction efficiency of the method.

For organic compounds found in aquatic environments at low concentrations is recommended the minimum application time of 7 days, so that the determination by an appropriate analytical technique is possible. ${ }^{16}$ The mass of each substance was found and then equation 5 was used to calculate the concentration in the samples.

$\mathrm{C}=\mathrm{M} \Delta \mathrm{g} / \mathrm{DAt}$

where $t$ is defined as time in seconds.

The concentration factor for the extraction procedure and sampling time were obtained by comparing the concentration of the substance determined by GC-MS/MS and the concentration calculated with equation 5 . The concentrations for EC, both in tap and river water, are shown in Table 2.

Table 2. Concentrations of emerging contaminants (EC) in tap and river water samples after 7 days of sampling with o-DGT

\begin{tabular}{lccc}
\hline Compound & $\begin{array}{c}\text { Tap water / } \\
\left(\mathrm{ng} \mathrm{L}^{-1}\right)\end{array}$ & $\begin{array}{c}\text { River water / } \\
\left(\mu \mathrm{g} \mathrm{L}^{-1}\right)\end{array}$ & $\begin{array}{c}\text { Concentration } \\
\text { factor }\end{array}$ \\
\hline OPN & $102 \pm 22$ & $11 \pm 6$ & 60 \\
NPN & $403 \pm 78$ & $10 \pm 5$ & 15 \\
TCS & $226 \pm 16$ & $0.6 \pm 0.4$ & 70 \\
BPA & $250 \pm 20$ & $0.05 \pm 0.02$ & 100 \\
\hline
\end{tabular}

OPN: 4-octylphenol; NPN: 4-nonylphenol; TCS: triclosan; BPA: bisphenol A. Standard deviation of six replicates $(n=6)$.

The concentration factor for each substance maintains a relationship with its diffusion coefficient. The NPN had the lowest value of D', so it presented the lowest concentration factor. The same premise applies to BPA, which has the highest D' and, consequently, a higher concentration factor. Further studies are needed to establish whether only the diffusion coefficient of the species is responsible for this behavior or the sorption by OASIS HLB after the diffusion through the gel also has influence.

All species of interest were found in tap and river water. In the tap water sample, NPN had the highest concentration and OPN the lowest. For the river sample, OPN and NPN were found in higher concentration and BPA presented the lowest concentration.

Alkylphenols are constituents of industrial and domestic products like detergents, plasticizers, and herbicides. Besides, OPN and NPN are used in the production of their 
ethoxylate derivatives (alkylphenol ethoxylates), one of the main nonionic surfactants used. ${ }^{28}$ Thus, due to its wide use, a significant amount of these compounds may be being introduced into aquatic environments, which would justify the concentrations found in this study.

BPA has been widely used in plastic products and it can be released to the environment through its use and handling. Nevertheless, BPA presented the lowest concentration in river water, which may be explained by its degradation in the environment. Dorn et al. ${ }^{29}$ observed a $96 \%$ decrease in the concentration of BPA between 3 and 5 days and had a half-life of 2.5 to 4 days.

Thus, the higher concentration of BPA in tap water may be associated with the fact that neither water treatment plants nor sewage plants are able to eliminate the contaminant. In addition, most commercial and residential hydraulic installations use polyvinyl chloride pipes and in turn use the plasticizer in order to ensure greater durability. ${ }^{30}$ In addition, the water supply system in Curitiba is integrated, and the water served to the university campus may be from at least three different water reservoirs. Last, the sample from Iraí River was taken downstream the city of Curitiba.

TCS was found in both samples at an intermediate concentration. This compound is an antimicrobial agent added to the composition of personal care products. Because of its widespread use in the last three decades, TCS has become one of the most frequently detected compounds in the effluent of treatment plants.

As the maximum exposure levels for these substances are not known, it is not possible to know if the concentrations found would be above or below the permitted level. However, only the presence of these compounds, especially in tap water, would be indicative that wastewater treatment plants are not able to eliminate these substances. Therefore, even at low concentrations, exposure to these substances over long periods could be a health risk to aquatic biota and humans.

The calibration curves $(n=3)$ presented satisfactory linearity within the concentration range: $5-150 \mu \mathrm{g} \mathrm{mL}^{-1}$ for OPN, NPN, TCS, and BPA. The coefficient of correlation $\left(r^{2}\right)$ exceeded 0.9900 for all analytes. The values of the LOD and LOQ are presented in Table 3.

Table 3. Instrumental values of the limits of detection and quantification

\begin{tabular}{lcccc}
\hline & OPN & NPN & TCS & BPA \\
\hline $\mathrm{LOD} /\left(\mu \mathrm{g} \mathrm{L}^{-1}\right)$ & 19.69 & 13.08 & 30.32 & 16.88 \\
$\mathrm{LOQ} /\left(\mu \mathrm{g} \mathrm{L}^{-1}\right)$ & 59.65 & 39.64 & 91.89 & 51.15 \\
\hline
\end{tabular}

OPN: 4-octylphenol; NPN: 4-nonylphenol; TCS: triclosan; BPA: bisphenol A; LOD: limit of detection; LOQ: limit of quantification.

\section{Conclusions}

For the first time in Brazil, the development and application of o-DGT samplers in aqueous matrices were carried out. The general objectives were achieved with an emphasis on the preparation of the binding phase and analytical determination by GC-MS/MS using the MRM mode. The o-DGT sampler developed in this study presented the necessary principles required by the DGT technique, providing the determination of organic substances belonging to some classes of EC in tap and river water.

The results indicate deficiencies in the removal of these compounds by the current wastewater treatment plant, and may not be a reality only in Curitiba and metropolitan area, but in other locations in Brazil. Thus, the o-DGT could be used in the future to monitor this class of substances in the environment and contribute to the creation of public policies on basic sanitation in the country.

\section{Acknowledgments}

The authors are thankful to Instituto Nacional de Ciências e Tecnologia Analíticas Avançadas (INCTAACNPq, 573894/2008-6 and 465768/2014-8), Financiadora de Estudos e Projetos (FINEP), Conselho Nacional de Desenvolvimento Científico e Tecnológico (CNPq). This study was also financed in part by the Coordenação de Aperfeiçoamento de Pessoal de Nível Superior, Brazil (CAPES), finance code 001 .

\section{Author Contributions}

Tiago Wacheski was responsible for the conceptualization, investigation, methodology, and writing original draft; Emerson L. Y. Hara for the investigation, methodology, and writing original draft; Bruno J. G. da Silva for the methodology and writing review and editing; Gilberto Abate for the methodology and writing review and editing; Barbara G. S. Soares for the investigation and methodology; Marco T. Grassi for the conceptualization, funding acquisition, project administration, supervision, and writing review and editing.

\section{References}

1. Farré, M.; Pérez, S.; Kantiani, L.; Barceló, D.; TrAC, Trends Anal. Chem. 2008, 27, 991.

2. Machado, K. C.; Grassi, M. T.; Vidal, C.; Pescara, I. C.; Jardim, W. F.; Fernandes, A. N.; Sodré, F. F.; Almeida, F. V.; Santana, J. S.; Canela, M. C.; Nunes, C. R. O.; Bichinho, K. M.; Severo, F. J. R.; Sci. Total Environ. 2016, 572, 138. 
3. Annunciação, D. L. R.; Almeida, F. V.; Hara, E. L. Y.; Grassi, M. T.; Sodré, F. F.; Quim. Nova 2018, 41, 782.

4. Farré, M.; Petrovic, M.; Gros, M.; Kosjek, T.; Martinez, E.; Heath, E.; Osvald, P.; Loos, R.; le Menach, K.; Budzinski, H.; de Alencastro, F.; Müller, J.; Knepper, T.; Fink, G.; Ternes, T. A.; Zuccato, E.; Kormali, P.; Gans, O.; Rodil, R.; Quintana, J. B.; Pastori, F.; Gentili, A.; Barceló, D.; Talanta 2008, 76, 580.

5. Geissen, V.; Mol, H.; Klumpp, E.; Umlauf, G.; Nadal, M.; van der Ploeg, M.; van de Zee, S. E. A. T. M.; Ritsema, C. J.; Int. Soil Water Conserv. Res. 2015, 3, 57.

6. Hara, E. L. Y.; da Silva, C. A.; Souza, R. S.; Colimo, A. G. S. C.; Grassi, M. T.; Curr. Anal. Chem. 2018, 14, 615.

7. Kuswandi, B.; Nitti, F.; Almeida, M. I. G. S.; Kolev, S. D.; Environ. Chem. Lett. 2020, 18, 129.

8. Chen, C.-E.; Zhang, H.; Jones, K. C.; J. Environ. Monit. 2012, $14,1523$.

9. Davison, W.; Zhang, H.; Nature 1994, 237, 546.

10. Chostak, C. L.; de Campos, M. S.; da Silva, S. B.; Abate, G.; Grassi, M. T.; Quim. Nova 2015, 38, 356.

11. dos Anjos, V. E.; Abate, G.; Grassi, M. T.; Braz. J. Anal. Chem. 2010, $1,187$.

12. Li, Y.; Chen, C. E. L.; Chen, W.; Chen, J.; Cai, X.; Jones, K. C.; Zhang, H.; J. Agric. Food Chem. 2019, 67, 6397.

13. Guibal, R.; Buzier, R.; Charriau, A.; Lissalde, S.; Guibaud, G.; Anal. Chim. Acta 2017, 966, 1.

14. Chen, W.; Pan, S.; Cheng, H.; Sweetman, A. J.; Zhang, H.; Jones, K. C.; Water Res. 2018, 137, 211.

15. Zhang, D.; Zhu, Y.; Xie, X.; Han, C.; Zhang, H.; Zhou, L.; Li, M.; Xu, G.; Jiang, L.; Li, A.; Water Res. 2019, 157, 292.

16. Fang, Z.; Li, K.; Li, Y.; Zhang, H.; Kevin, C.; Liu, X.; Liu, S.; Ma, L. Q.; Luo, J.; Environ. Sci. Technol. 2019, 53, 11223.
17. Challis, J. K.; Almirall, X. O.; Helm, P. A.; Wong, C. S.; Environ. Pollut. 2020, 261, 114092.

18. Chen, C.-E.; Zhang, H.; Ying, G.-G.; Jones, K. C.; Environ. Sci. Technol. 2013, 47, 13587.

19. Fauvelle, V.; Castro-Jiménez, J.; Schmidt, N.; Carlez, B.; Panagiotopoulos, C.; Sempéré, R.; Front. Mar. Sci. 2018, 5, 295.

20. Kotowska, U.; Kapelewska, J.; Sturgulewska, J.; Environ. Sci. Pollut. Res. 2014, 21, 660.

21. Siddique, S.; Kubwabo, C.; Harris, S. A.; Emerging Contam. 2016, 2, 204.

22. Ahel, M.; Giger, W.; Chemosphere 1993, 26, 1461.

23. Challis, J. K.; Hanson, M. L.; Wong, C. S.; Anal. Chem. 2016, 88, 10583.

24. Chen, C. E.; Zhang, H.; Ying, G. G.; Zhou, L. J.; Jones, K. C.; Environ. Int. 2015, 85, 284.

25. Qiu, Y.-W.; Zhang, G.; Guo, L.-L.; Zheng, G. J.; Cai, S.-Q.; Mar. Environ. Res. 2010, 70, 219.

26. Chen, W.; Li, Y.; Chen, C. E.; Sweetman, A. J.; Zhang, H.; Jones, K. C.; Environ. Sci. Technol. 2017, 51, 13274.

27. Guibal, R.; Buzier, R.; Lissalde, S.; Guibaud, G.; Sci. Total Environ. 2019, 693, 133537.

28. Soares, A.; Guieysse, B.; Jefferson, B.; Cartmell, E.; Lester, J. N.; Environ. Int. 2008, 34, 1033.

29. Dorn, P. B.; Chou, C.; Gentempo, J. J.; Chemosphere 1987, 16, 1501.

30. Lamprea, K.; Bressy, A.; Mirande-Bret, C.; Caupos, E.; Gromaire, M.-C.; Environ. Sci. Pollut. Res. 2018, 25, 21887.

Submitted: December 11, 2019

Published online: August 5, 2020 